\title{
Property for Fatigue Crack Propagation of Friction Stir Welded 2024-T3 Aluminum alloy
}

\author{
Masakazu Hirose ${ }^{1, *}$, Motoo Asakawa ${ }^{2}$, Takao Okada ${ }^{3}$, \\ Shigeru Machida ${ }^{3}$, Toshiya Nakamura ${ }^{3}$, Shuji Kishishita ${ }^{4}$, \\ Kazuya Kuwayama $^{5}$, Shinya Fujita ${ }^{5}$, Takuya Noguchi ${ }^{1}$ \\ ${ }^{1}$ The Graduate School of Science and Engineering, Waseda University, Tokyo 169-8555, Japan \\ 2 Department of Applied Mechanics and Aerospace Engineering, Waseda University, Tokyo 169-8555, Japan \\ ${ }^{3}$ Japan Aerospace Exploration Agency, Tokyo 181-0015, Japan \\ ${ }^{4}$ Advanced Engineering Services, Tsukuba 305-0032, Japan \\ ${ }^{5}$ Alumnus of the Graduate School of Waseda University, Tokyo 169-8555, Japan \\ * Corresponding author: m_hirose1989@ruri.waseda.jp
}

\begin{abstract}
In this study, crack propagation tests were conducted to clarify property for the fatigue crack propagation of Friction Stir Welded (FSW) 2024-T3 aluminum alloy. FSW panel has residual stress around weld line and the longitude residual stress is higher around it. The peak tensile residual stress is about $180 \mathrm{MPa}$ in this case. To understand fatigue crack growth property on FSW panel, crack opening stress measurement of the base material and FSW joint using an extensometer with the modified tool is also conducted during the crack growth test. The modified tool is jig to mount the extensometer to the specimen with magnets. The test results indicate that the accuracy of crack opening stress measurement is improved. In addition, the crack growth acceleration and decelerate around the FSW line under the low applied stress range (25 $\mathrm{MPa})$ is bigger than that under high applied stress range $(50 \mathrm{MPa})$. This means the effect of residual stress under low stress range is relatively larger than that under high stress range.
\end{abstract}

Keywords: Friction Stir Welding, Fatigue Crack Growth Propagation, Residual Stress, Crack Opening Stress

\section{Introduction}

Friction stir welding (FSW) is one of recently developed welding process ${ }^{[1]}$ as shown in figure 1 . It has the capability of welding high strength Aluminum alloys of $2 \mathrm{xxx}$ and $7 \mathrm{xxx}$ type which are difficult to weld by conventional welding. FSW has applied many structures such as trains, rockets and ships. From point of reducing production cost and structural weight, FSW is expected to be applied to commercial aircraft primary structures as an alternative to riveted joints. FSW was firstly used on a normal category aircraft "Eclipse 500" by Eclipse Aviation in 2006. However, the safety factor of FSW joint is estimated high in this aircraft. So far the study of FSW has been not sufficient to meet a damage tolerance. The Federal Aviation Regulations (FARs) on damage tolerance and fatigue evaluations of aircraft structures require understanding of the locations of fracture origin and the fatigue crack propagation property of the materials for aircrafts. To apply the structures jointed by FSW on aircrafts, the investigation of relationship between fatigue crack propagation property and residual stress on FSW panel is particularly significant. In case of FSW, the fatigue crack propagation rate is accelerated by the tensile residual stress around weld line as a result of non-uniform deformation caused by welding heat. Therefore, the explanation is required to determine an effect of residual stress on the crack propagation in the FSW panel. The aim of this study is to accurately evaluate the crack growth rate on FSW panel. The significance of this study is to focus on the crack opening stress to predict crack growth rate on FSW panel.

Our final goal of this research is to accurately predict the crack growth rate using FEM analysis. To achieve this goal, we have conducted the crack growth test ${ }^{[2-5]}$. In this paper we report the crack growth test results of the FSW panel with different applied stress and crack opening stress of the base material and FSW joint using an extensometer with the modified tool. 


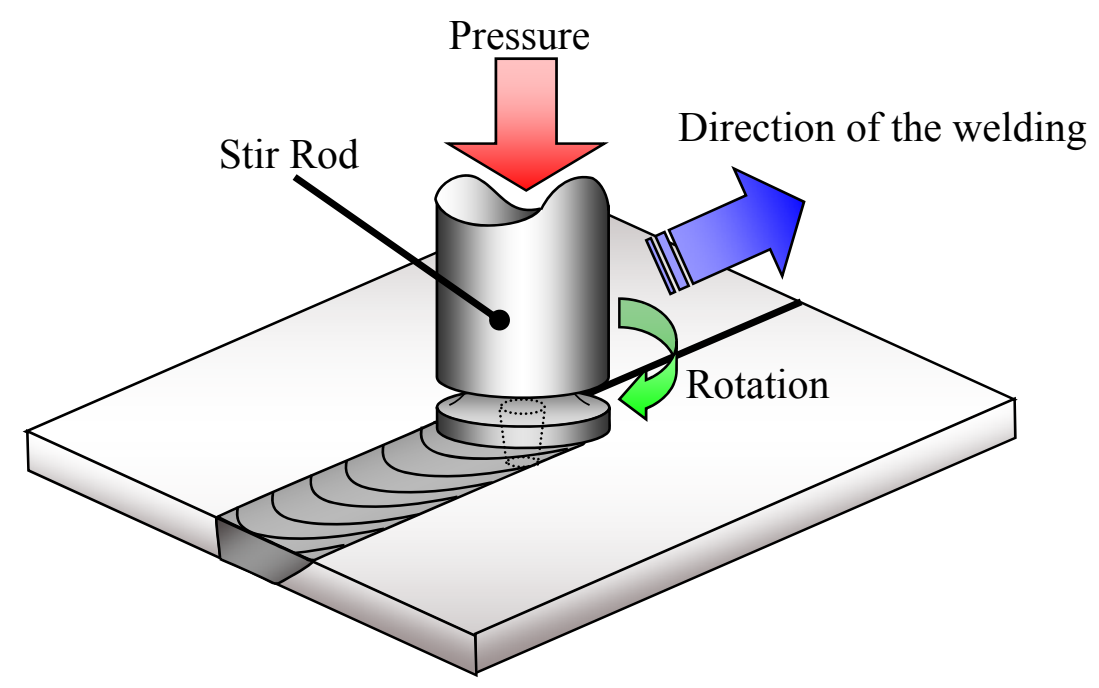

Figure 1. Schematic scheme of Friction Stir Welding

\section{Material, specimen and method}

The crack propagation tests were conducted, in accordance to the procedure in ASTM E647-08 ${ }^{[6]}$ standard test method. Sheet of 2024-T3 with a thickness of $2 \mathrm{~mm}$ were joined by FSW to form a butt joint. It is fabricated by Japanese aircraft manufacturer. The situations of Base metal panels and FSW panels are shown as Figure 2. Table 1 shows the list of specimens. All specimens have a center hole and notches as the initial flaw. All FSW panels have been welded by same welding procedures. So the level of residual stress is presumed to become same as each FSW panels. Figure 3 shows the result of measuring the residual stress in the vicinity of the weld line.

The crack growth test is subject to cyclic load with stress range: $\Delta \sigma=25,50,75 \mathrm{MPa}$, stress ratio: $R=0.1$ and load frequency: $f=5 \mathrm{~Hz}$. The crack length was measured using a CCD camera. And we have installed the extensometer on specimens to measure crack opening displacement in order to evaluate the crack opening stress based on the compliance method which is improved by Chung et. al. ${ }^{[7]}$. In this test, the displacement above and below the hole was measured by an extensometer; the crack opening stress was determined on the basis of the change in the compliance of the specimen. We had installed the extensometer with bolts. In this study, the extensometer has been installed with modified tools. The modified tool is jig to mount the extensometer to the specimen with magnets.

Table 1. The list of specimens

\begin{tabular}{|c|c|c|c|}
\hline No. & $\begin{array}{c}\text { Base metal or } \\
\text { FSW panel }\end{array}$ & Specimen size & $\begin{array}{c}\text { stress range } \\
\Delta \sigma \mathrm{MPa}\end{array}$ \\
\hline 1 & \multirow{2}{*}{ Base metal } & Large size & 50 \\
\hline 2 & & Small size & 25 \\
\hline 3 & \multirow{3}{*}{ FSW panel } & Large size & 75 \\
\hline 4 & & Large size & 50 \\
\hline 5 & & Small size & 25 \\
\hline
\end{tabular}




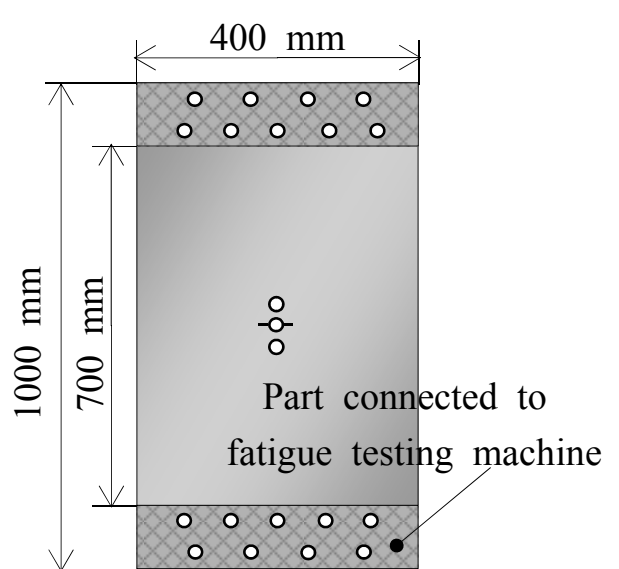

(a) Base metal

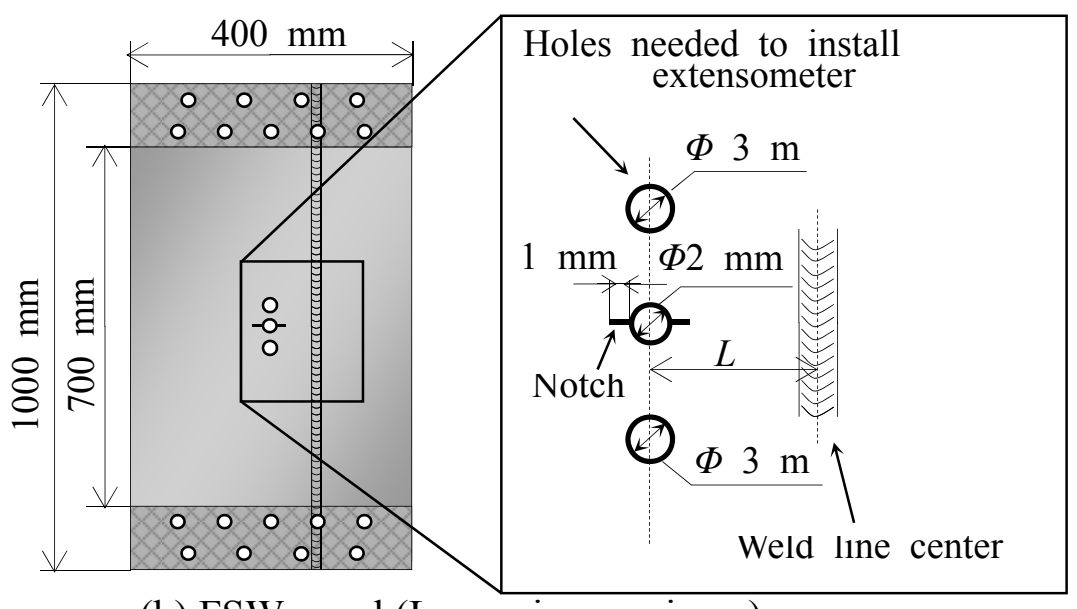

(b) FSW panel (Large size specimen)

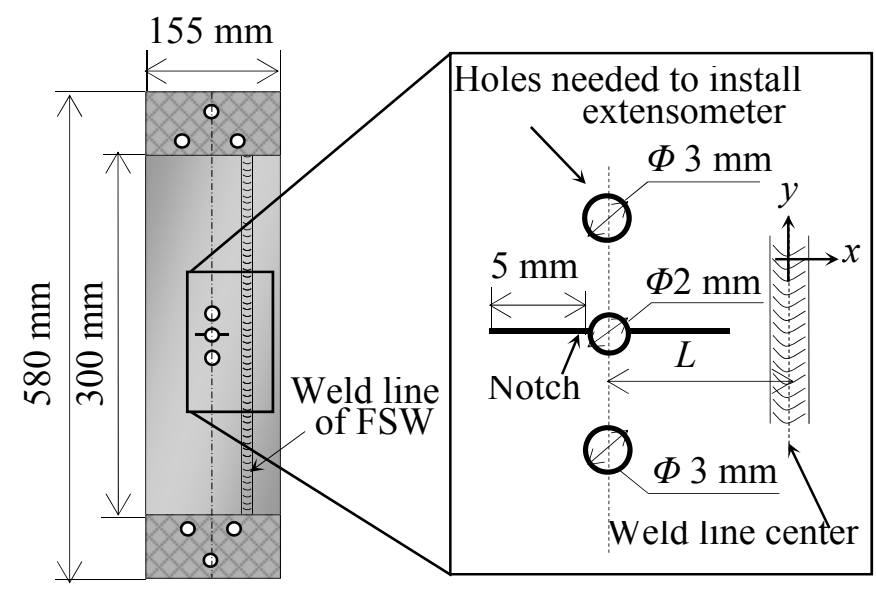

(c) FSW panel (Small size specimen)

Figure 2. Specimen's dimensions

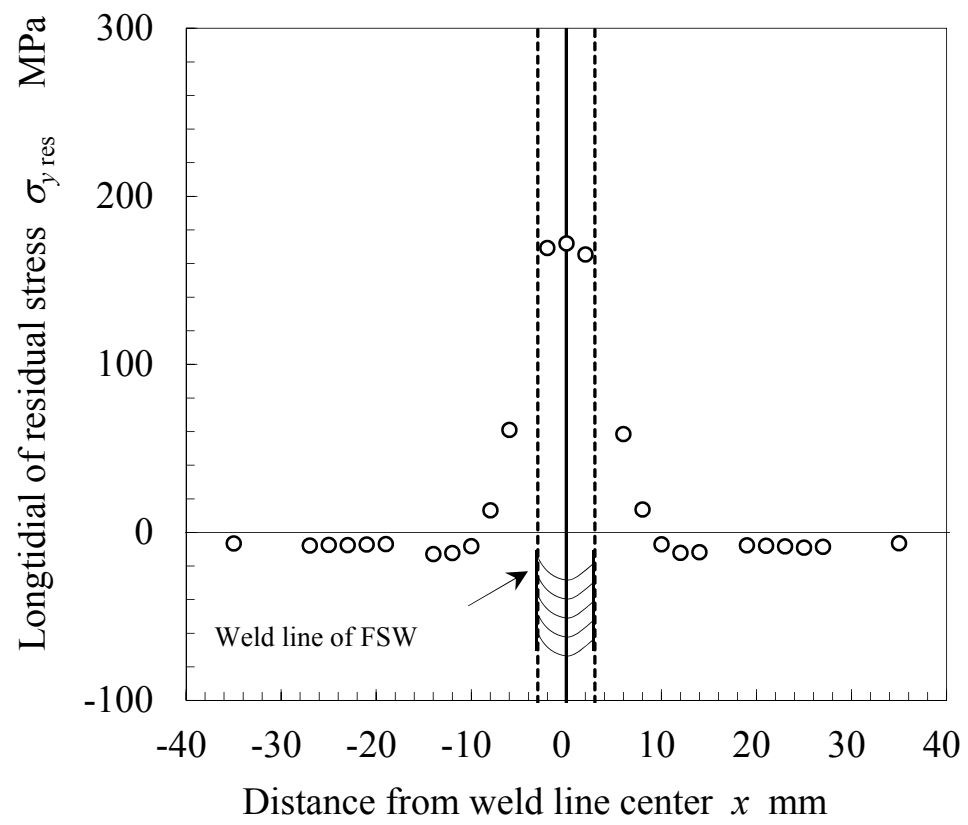

Figure 3. Relationship between longitudinal of residual stress and distance from weld line center 


\section{Result and discussion}

\subsection{Improvement of the jig}

We need to mount an extensometer on specimens when we measure the crack opening stress. In case of $\Delta \sigma=50$ and $75 \mathrm{MPa}$, the extensometer was installed on specimen with bolt jig as shown in Figure 3(a) and measure the crack opening displacement. However, if tightening torque of bolts is not appropriate, the extensometer is not fixed on specimen and it is drifted. Therefore, we improved jig to mount the extensometer to the specimen tightly with magnets as shown in Figure 3(b).

To verify that the magnet jig can measure the crack opening stress, we measured the crack opening stress of base metal and compare the result of both jigs. In this study, we decided that crack is opening completely when the relative compliance offset become $5 \%$. This method is based on Chung's research ${ }^{[7]}$. In case of using bolt jig, the result of relative compliance offset is unstable and become greater than $5 \%$ when the crack tip is not opening. So judgment of crack opening had been difficult. In case of using magnet jig, the relative compliance offset is stable and become less than $5 \%$ when the crack tip is not opening. Therefore, the accuracy of crack opening stress measurement is improved by the magnet jig.

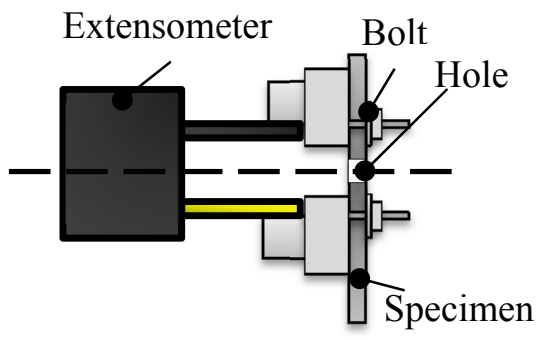

(a) Bolt jig

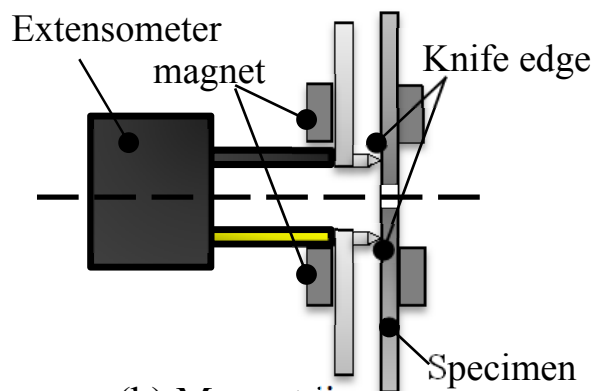

(b) Magnet jig

Figure 3. Installing extensometer

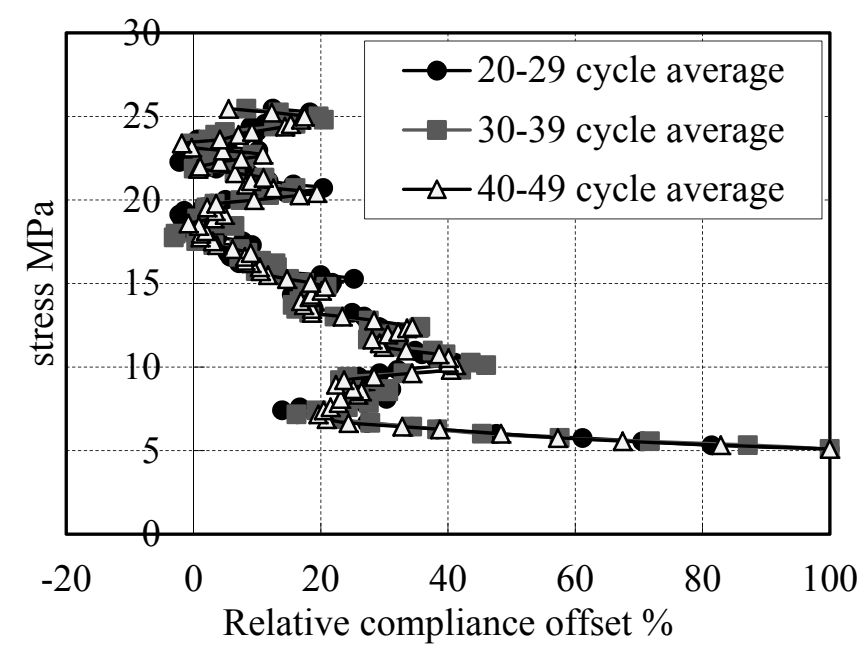

Figure 4. Determination of crack opening stress (bolt, $\mathrm{a}=25.93 \mathrm{~mm}$ ) 


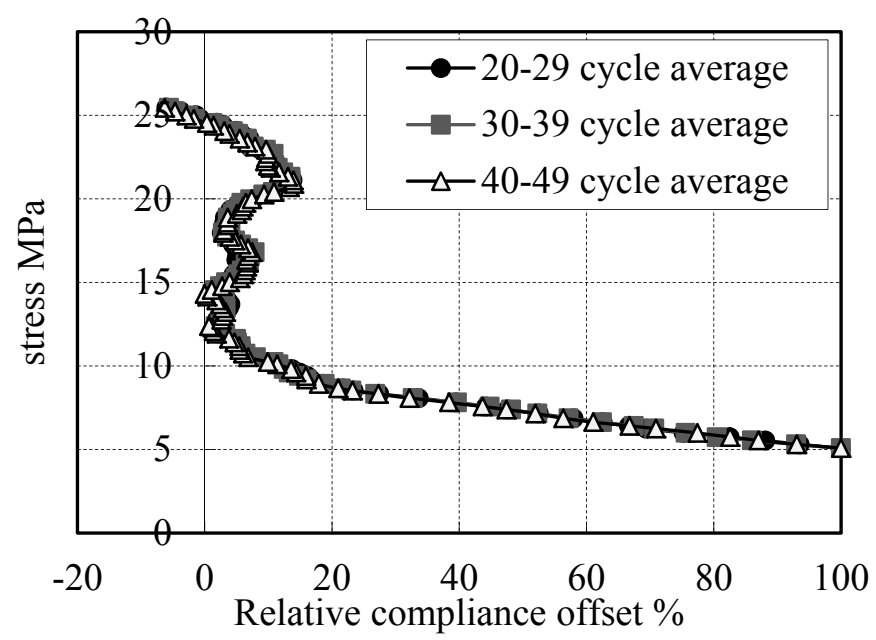

Figure 5. Determination of crack opening stress (magnet, $\mathrm{a}=25.93 \mathrm{~mm}$ )

\subsection{The result of crack opening stress measurement}

The effective stress range, $\Delta \sigma_{\text {eff, }}$ which is calculated using the maximum stress, $\sigma_{\max }$, has one to one correlation to the crack growth rate. Here, $\Delta \sigma_{\text {eff }}$ is calculated by the following equation 1.

$$
\Delta \sigma_{e f f}=\sigma_{\max }-\sigma_{o p}
$$

Elber ${ }^{[8]}$ shows in full detail that The rate of crack propagation can be evaluated uniformly by using the effective stress range.

So the crack growth rate can be predicted by crack opening stress. To use the effective stress range, we have to accurately measure the crack opening stress of FSW panel.

There are some studies calculating crack opening stress of base metal by using empirical equations. Some of them, we have used empirical equations for 2024-T3 proposed by schijive ${ }^{[9]}$ as eq. 2 and eq. 3 .

$$
\begin{gathered}
U=0.55+0.3 R+0.1 R^{2}, \\
\therefore \sigma_{o p}=\sigma_{\text {max }}-\left(0.55+0.3 R+0.1 R^{2}\right) \Delta \sigma .
\end{gathered}
$$

Figure 6 shows the result of crack opening stress measurement in each crack length. In addition, the calculated values obtained by the Schijive's equation and the experimental result of base metal $(\Delta \sigma$ $=75 \mathrm{MPa})$ are shown together.

In case of $\Delta \sigma=75 \mathrm{MPa}$, the unti-buckling pate which suppress the out of plane deformation was used and measured with bolt jig. However, in case of $\Delta \sigma=25 \mathrm{MPa}$, the unti-buckling plate was not used and measured with magnet jig. Therefore, the width of the variability of the measurement results is reduced by about $58 \%$. Moreover, the result of measurement is same as the calculated values obtained by Schijive equation. For that reason, the validity of this measurement was confirmed and the test results indicate that the accuracy of crack opening stress measurement is improved.

Next, focus on the result of FSW panel as shown part A in figure 6. After crack tip invasion into weld line, crack opening stress is reduced substantially. Then, crack opening stress is asymptotic to the result of base metal as go away from weld line. From this result, the effect of residual stress is reduced when a position of crack tip is taken enough away from the weld line. 


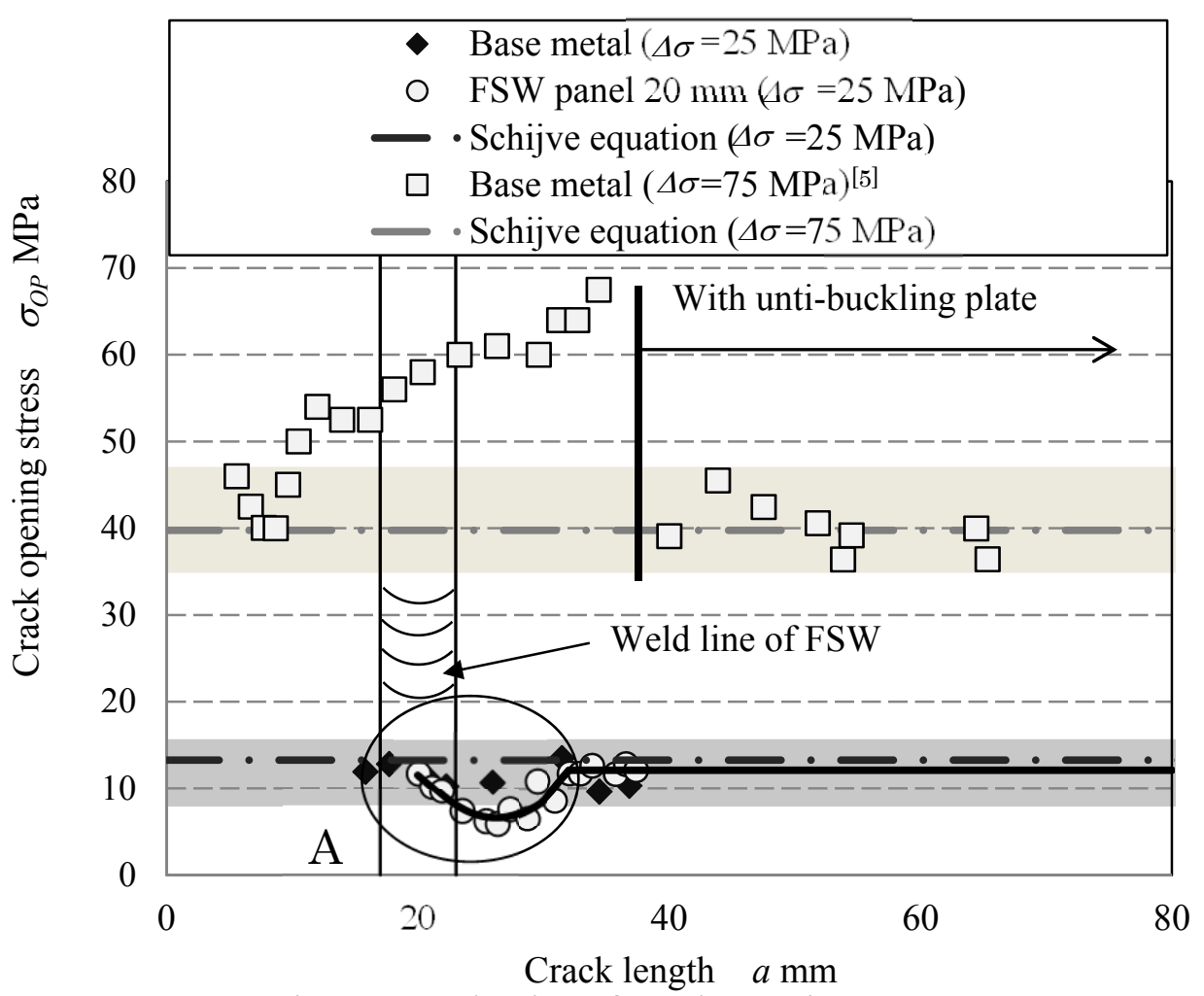

Figure 6. Behavior of crack opening stress

\subsection{Effect of residual stress on crack propagation rate}

We conducted crack growth tests with three types of external load conditions; $\Delta \sigma=25,50,75 \mathrm{MPa}$. First, The results of $\Delta \sigma=50,75 \mathrm{MPa}$ are shown in Figure 8. The stress intensity factor range is calculated by equation 4 .

$$
\Delta K=\Delta \sigma \sqrt{\pi a} \cdot F(a)
$$

Here, $\mathrm{F}(\mathrm{a})$ is a correction factor. The reason why the position of weld line of FSW is different is because these two tests are different in stress range $\Delta \sigma$.

The maximum of the acceleration ratio of the crack growth rate for the FSW panel against the base material is 1 to $2 \mathrm{~mm}$ far away from the weld line after crack tip passes it. In case of $\Delta \sigma=50 \mathrm{MPa}$, the acceleration ratio is 2.1 , and $\Delta \sigma=75 \mathrm{MPa}$ the ratio is 2.3 . The residual stress influences the crack growth rate. The FSW panels have the same level of residual stress distribution. So in case of external stress is high, the effect of residual stress is expected relatively low. This means the acceleration of crack growth rate for that situation is also low. However in this experiment, the difference on the acceleration ratio for crack growth rate is almost same at this two stress level; $\Delta \sigma$ $=50,75 \mathrm{MPa}$.

The result of $\Delta \sigma=25 \mathrm{MPa}$ is shown in Figure 9. From the figure, it is observed that the crack propagation rate is decelerated by the compressive residual stress when the crack tip is located before the weld line. After the crack tip had moves on the weld line, the crack propagation rate is accelerated by the tensile residual stress. Finally, when the crack tip is located after the weld line, the crack growth rate is gradually approached to that of the base metal. In case of $\Delta \sigma=25 \mathrm{MPa}$, the acceleration ratio of the crack growth rate for the FSW panel against the base material is 3.7.

The acceleration ratio of each stress range is shown in Figure 10. In summary, the crack propagation rate is affected by the residual stress and stress range $\Delta \sigma$. All FSW panel using in this study is made 
under the same FSW condition. Therefore, residual stress of all specimens is identical. So, in the case of $\Delta \sigma=25 \mathrm{MPa}$, the effect of residual stress is relatively high. This means the acceleration and deceleration of crack growth rate for that situation is also high.

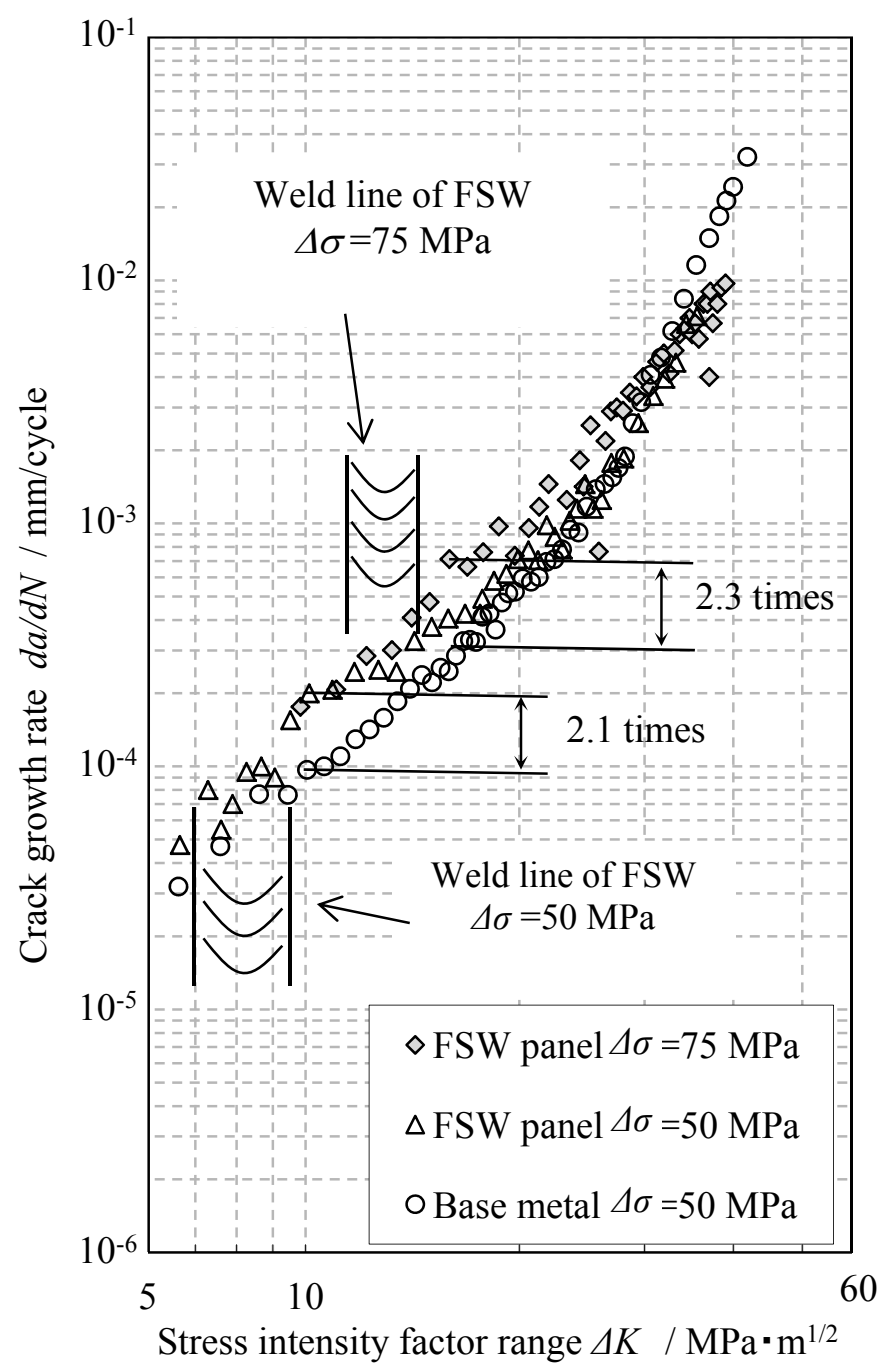

Figure $8 . \mathrm{da} / \mathrm{dN}-\Delta \mathrm{K}$ curves for different external stress 


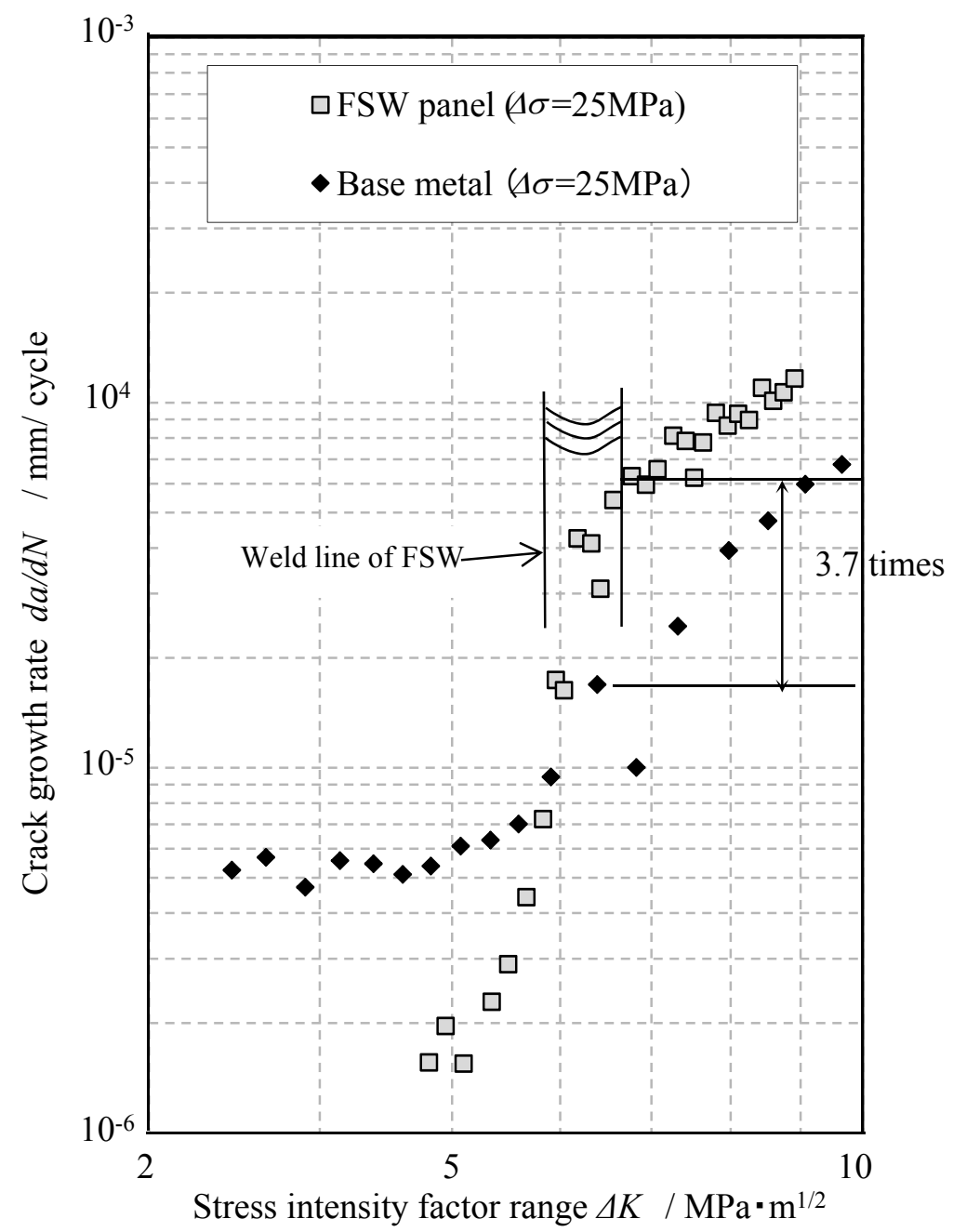

Figure 9. da/dN- $\Delta \mathrm{K}$ curves $(\Delta \sigma=25 \mathrm{MPa})$

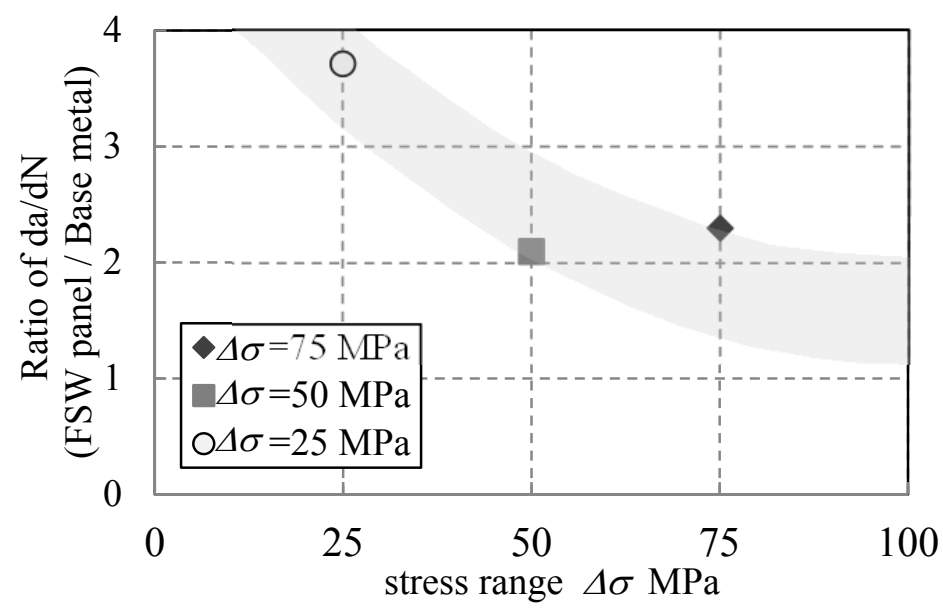

Figure 10. Comparison of fatigue crack growth rate 


\section{Conclusions}

Fatigue crack growth test were conducted in order to evaluate the effect of residual stress field on crack growth propagation. The results are as follows:

(1) The extensometer can be installed tightly on the specimen by using the modified jig with magnet. The test results indicate that the accuracy of crack opening stress measurement is improved.

(2) Stress ranges between $50 \mathrm{MPa}$ and $75 \mathrm{MPa}$ does not clearly affect the acceleration ratio for crack growth rate against the base material. On the other hand, in the case of $\Delta \sigma=25 \mathrm{MPa}$, the effect of residual stress on the acceleration ratio for crack growth rate against the base material is relatively high. This means the acceleration and deceleration of crack growth rate for that situation is also high. In this test, the acceleration ratio of the crack growth rate for the FSW panel against the base material is 3.7 .

\section{References}

[1] G. Bussu, P E. Irving, Static and fatigue performance of Friction Stir Welded 2024-T351 aluminum joints, Proceedings of 1st International Symposium on Friction Stir Welding, 1999.

[2] K. Kuwayama, M. Asakawa, T. Okada, T. Nakamura, S. Machida, S. Fujita, Fatigue crack propagation property of friction stir welded 2024-T3 aluminum alloy, APISAT 2009, CD.

[3] T. Okada, K. Kuwayama, S. Fujita, M. Asakawa, T. Nakamura, Properties of fatigue crack propagation in friction stir welded 2024-T3 aluminum alloy, ICAF 2009, pp. 899-908

[4] S. Fujita, M. Asakawa, T. Okada, T. Nakamura, S. Machida, K. Kuwayama, Evaluation of FSW Fatigue Crack Growth Rate Based on Crack Closure Phenomenon, APISAT 2010, CD.

[5] T. Noguchi, M. Asakawa, T. Okada, T. Nakamura, S. Machida, K. Kuwayama, S. Fujita, Property for Fatigue Crack Propagation of Friction Stir Welded 2024-T3 Aluminum Alloy, APISAT 2012; CD.

[6] American Society for Testing and Material, Standard Test Method for Measurement of Fatigue Crack Growth Rates, ASTM E647-08, 2008

[7] Y. Chung, J. Song, Improvement of ASTM compliance offset method for precise determination of crack opening load, International Journal of Fatigue 31, 2009, pp.809-819

[8] W. Elber, The Significance of Fatigue Crack Closure, ASTM STP 486, 1971

[9] J.Schijve, Some Formulas for the Crack Opening Stress Level, Engineering Fracture Mechanics, 1981, pp.461-465. 